\title{
INTRODUCTION
}

\section{Innovations in Gender Equality and Women's Empowerment: Understanding the Role of International Development Volunteers as Transnational Actors}

\author{
Rebecca Tiessen and Benjamin J. Lough
}

This special issue of Voluntaris helps us understand the distinctive contributions of international development volunteers (IDVs) to gender equality and women's empowerment (GEWE) programming in the Global South. Building on critical development theory, feminist theory, subaltern studies and human capabilities literature, this collection assesses the complex roles and impacts of IDVs as transnational actors on partner organization programming and the promotion of gender equality outcomes.

Global disparities and limited opportunities for women continue to catch them in traps of inequality. As articulated in Sustainable Development Goal (SDG) $\# 5$, achieving gender equality and empowering all women and girls is essential to accelerating and achieving sustainable development. Gender equality is more than a basic human right, it also creates a multiplier effect with the capacity to magnify all other development outcomes. Indeed, the thematic priority of gender equality chosen for this special issue emerged from previous research as a development outcome that results in heightened capacity development in international volunteering programs needed to achieve other SDGs.

Previous research conducted by the special issue editor(s) resulted in an improved understanding about how diverse forms of international volunteering are associated with capacity building and development outcomes from the perspective of partner organizations (see Lough/Tiessen 2018; Lough/Tiessen/Lasker 2018; Tiessen/Grantham/Lough 2018; Tiessen/Lough 2018). However, the exploratory research included in these earlier publications also uncovered additional gaps of express interest to volunteer-involving organizations. Among these diverse organizations, Volunteer Cooperation Agencies (VCAs) were specifically interested in understanding how the distinctive characteristics of volunteering can enhance or inhibit local capacities in pursuit of SDG targets - particularly in areas such as gender equality. Furthermore, this previous research provided a high degree of quantitative findings that highlighted overarching trends and experiences but lacked 
sufficient qualitative information about the nature of the partnerships and collaborations in support of specific programming strategies and outcomes, especially in the area of gender equality programming.

While gross inequalities still exist in access to paid employment, equal opportunities in the labour market, equal rights to land and property ownership, and equal gender division in relation to unpaid care and domestic work, this research shines a light on how IDVs address these challenges as they expose and advocate for equality in their direct engagements with host communities, as well as their advocacy efforts abroad.

The data collected for this special issue underscore several core ways that IDVs contribute to GEWE in areas such as: capacity building, intercultural relations, women-focused versus gender-focussed programming, perceptions of feminism, social innovation and women's economic empowerment, addressing masculinities and the inclusion of men and boys, women's political and economic participation, and grass roots impacts.

Employing ten country case studies (Ghana, Kenya, Malawi, Tanzania, Senegal, Ghana, Nepal, Vietnam, Guatemala and Peru), the individual papers included in this special issue summarize data collected between 2018-2019 and analysed between 2019-2020. The data were collected and analysed by emerging Northern and Southern scholars that include locally based researchers in the Global South, international students, and Canadian researchers. These teams of transnational researchers coded and analyzed a full set of interview transcripts and coded the material to identify common themes through content analysis. Several of these researchers then summarized their analyses into the chapters that became the body of this special collection. The research process encompassed a collaborative research design, shared data analysis and the co-creation of knowledge with practitioner organizations including Volunteer Cooperation Agencies (VCAs) that are part of Canada's Volunteer Cooperation Program (VCP) as well as partner organizations that receive volunteers in the Global South. This collaborative research design and writing process underscore the dynamic and reciprocal ways that knowledge about - and commitments to - gender equality are shared through transnational activities and development programming involving IDVs.

\section{Introduction}

Addressing gender inequality in international development requires broad ranging commitments from diverse organizations and individuals. In this collection, we examine the experiences of partner organizations and communities in the Global South who have worked with IDVs and their reflections on IDV support to GEWE. International development volunteers are distinguished from alternative forms 
of international volunteering for "international understanding" with a focus on the hosting community or organization as the prime beneficiary, with key aims of empowerment and capacity building (Lough/Tiessen 2018). Throughout the papers in this collection, the role and impact of IDVs are viewed through a transnational actor lens, emphasizing the relationships that emerge through the interactions between IDVs and partner organization staff.

This introductory paper provides an overview of IDVs as development actors: their roles, functions and affiliations. We were particularly interested in learning about Canadian IDVs who are taking part in Canada's Volunteer Cooperation Program (VCP) and the role of the VCP in facilitating IDV connections with partner organizations as part of their broader programmatic objectives. However, partner organizations provided a number of examples of IDVs from a large range of countries and therefore the data are not reflective solely of Canadian transnational actors specifically. The interviews also focused on priorities guiding the VCP and other foreign aid funding as outlined by Global Affairs Canada (GAC) through its 2017 foreign aid policy titled Canada's Feminist International Assistance Policy (FIAP). Data collected during interviews provided insights specific to knowledge about Canada's FIAP.

The thematic focus on women and girls is a core priority of GAC. Canada's FIAP (GAC 2017) is committed to ensuring no less than 95 percent of Canadian bilateral aid advances gender equality and promotes the empowerment of women and girls by 2021-2022 (GAC 2017). The Government of Canada recognizes that the lack of women's economic opportunities comes at great cost to economic prosperity and growth (GAC 2017). Thus, concerns for gender equality have been longstanding issues for critical discourse (e.g. postcolonial feminism) and have remained an ongoing commitment at every major global summit in the past three years. To better inform these outcomes, the research contained in this collection asked communities to specifically reflect on how the priorities of FIAP influence their lives.

This paper then turns to an overview of the methodology employed in designing and carrying out the empirical research, including the specific methods of data collection and analysis used to understand the themes and conclusions that emerged in the separate papers included in this collection. We end this paper with a brief overview of individual papers included in the special collection. This roadmap to the issue reviews the key arguments and messages of each of the papers and summarizes how these papers advance our knowledge in line with specific thematic areas of focus in relation to the role and impact of IDVs as transnational actors promoting GEWE in collaboration with partner organizations in the Global South. Taken together these papers illustrate the distinctive contributions of IDVs and the significance of transnational interactions for partner organizations working together to promote GEWE. 


\subsection{The Role of IDVs as Actors in Transnational Relations}

IDVs involved in transnational relations engage in international relations as nonstate actors in important ways (Hagel 2011; Clarke 2005). Although diverse types of international volunteers may engage with transnational relations with a focus on "international understanding" (see Lough/Tiessen 2018), we are interested in better understanding the role of IDVs, who prioritize the needs and capacities of hosting communities and organizations as their primary target.

The concept of transnational relations is an encompassing term that covers a range of interactions but with a specific emphasis on human agency (Risse 2013). Nye and Keohane (1971: 332) defined transnational relations as: "Regular interactions across national boundaries when at least one actor is a non-state agent". The processes and forces of globalization have facilitated growing transnational linkages across diverse agents including civil society actors, "encouraging greater civil society engagement in some areas of Canadian foreign policy decision-making after 1968" (Macdonald 2018: 359). One of the distinctive features of transnational relations, however, is the way that globalization is viewed from - and enacted as - "globalization from below" (Della Porta/Massimiliano/Mosca/Reiter 2006), or an 'actor-centred' approach (Risse 2013) and focuses attention on the role of transnational actors "in social policymaking, encouraging critical engagement and examination of their behavior and activities" (Shriwise 2020:34).

Transnational relations are also characterized by largely informal ties as well as the "diffusion of ideas and information, with little formal organizational substance" (Macdonald 2018). These relations, however, are linked to the expansion of global civil society which is deemed "a crucial component for championing positive transformative change, including gender equality, inclusion, respect for diversity and human rights, peace and security, and development" (GAC 2017: no page number).

Scholarship on transnational relations has also highlighted the role of transnational actors in norm diffusion (Landolt 2004) and knowledge production (Haas/ Repenning, 2018). Asking the question: "How do norms travel?", Zwingle (2012: 115) calls for more sophisticated analyses of the roles and impacts of transnational actors, pointing out that "global to local flows of norms inherent in most of the global norm diffusion literature is simplistic". When it comes to the transnational diffusion of knowledge and norms in comparison with intra-national relations, unequal power relations between stakeholders in the Global North and Global South require a more critical reflection on the nature and impact of postcolonial power structures.

While transnational actors, and IDVs in particular, can participate in diverse forms of norm diffusion from human rights to democratic governance, the focus in this collection is on norm and knowledge diffusion through transnational 
relationships, with a focus on feminist principles and the values of gender equality. Transnational interactions between IDVs and partner organization staff in the Global South highlight how understandings of GEWE are shaped over time. IDVs are linked to enhanced confidence for GEWE programming and are known to offer alternative strategies, model different gender practices, and shape attitudes and behaviours related to gender equality (Tiessen/Rao/Lough 2021). Given concerns about cultural imperialism, norm diffusion around gender equality and feminist values is often met with resistance and reinterpretation in foreign communities. In other contexts, however, the diffusion of gender equality as a fundamental human right is widely embraced and accepted as an effective method for allyship and in the promotion of changes to discriminatory norms in pursuit of equal opportunities for women and girls.

\subsection{Defining IDVs}

Devereux (2008: 359 - 360) describes the distinctive characteristics of IDVs as volunteers with humanitarian motivations; a commitment to reciprocal benefit; willingness to live work under local conditions and with a long-term commitment; local accountability and North-South partnership; and emphasis on tackling causes rather than symptoms of poverty in their work. Supervision of the day-today work of IDVs is performed by the local organization and IDVs are primarily accountable to this local organization.

With this baseline definition in mind, a simple definition of international development volunteering is complicated by the diverse program modalities that exist. It is important to distinguish between the different forms of transnational relations that are often characterized in terms of directional flows such as South-South or North-South or South-North volunteering. Other important differences include the length of the volunteer placement. While many IDVs live abroad for one year or longer, short term but skilled volunteers of six months or less can also contribute substantially to development (see Lough/Tiessen 2018).

One important distinction that separates the forms of international volunteering, however, is the differences between learner-centred or development-centred placements. Some of the IDVs discussed during interviews would fall under the category of learning-focused because they were students or recent graduates with limited professional skills to share at the time of their IDV placement. For the sample studied in this special issue we consider IDVs who fit the category of North-South volunteers who generally have professional skills to share, and, for the most part, are Canadian citizens travelling abroad. Partner organization staff were asked to share their experiences of working with IDVs. Distinguishing between the nationalities of IDVs can be challenging for some organizations since they may host volunteers from multiple countries. During interviews, partner organization staff were asked 
to try to think of their particular experiences working with Canadian IDVs and to consider the role and impact of IDVs who were placed through Canada's Volunteer Cooperation Program (VCP).

Given the importance of the VCP program to the majority of the volunteer placements, we provide a short summary of it here. Since the 1960s, the Government of Canada has sent tens of thousands of international volunteers to work in development projects around the world through Canada's VCP. Between 2015 and 2020, The Volunteer Cooperation Program (VCP), supported by the Government of Canada, funded twelve IDV projects managed by 15 Volunteer Cooperation Agencies (VCAs) to facilitate volunteer placements for 10,000 IDVs to more than 50 countries (Government of Canada 2020). The objectives of Canada's VCP align with the definition and distinctive characteristics of IDVs noted above including: increasing the capacity of developing-country partners to deliver sustainable development results in response to local needs; and enhancing Canadians' participation in Canada's development efforts to promote a better understanding of development challenges (Government of Canada 2018). While the Volunteer Receiving Organizations that host these volunteers complete mid- and end-term reports and evaluations of these IDV programs, these evaluations are not in the public domain. Therefore, little is known about the roles of IDVs, their positive or negative impacts, and their distinctive contributions to the delivery of programs of explicit interest to the Government of Canada, including programs with clearly-defined priorities for the promotion of gender equality.

\section{Filling Gaps in Scholarship on International Development Volunteering}

Research and scholarship on international development volunteering have addressed several themes worth highlighting in this collection including the pros and cons of international engagement - particularly in the case of North-South volunteering. International volunteerism can "facilitate social integration and social inclusion", encourage "cross-cultural exchange and knowledge-sharing" as well as advance the United Nations Sustainable Development Goals (SDGs) (Lough 2015: 3; Tiessen 2018: 1). Volunteers and the VCAs that facilitate their placements "develop partnerships and are able to contribute to development assistance" (Tiessen 2018: 1).

Much of the literature to date has focussed on motivations and experiences of international volunteers (Helms/McKenzie 2014; Lee/Won 2018; Lough/Xiang 2016; Johnson 2015; L. Chen/J. Chen 2011). Recently, scholarship has also highlighted the impact of IDVs, focussing on effectiveness and impact of international volunteering (Palacios 2010; Smith 2014; Trau 2015; Louiseau et al. 2016; Campbell Lehn 2015; Lough/Tiessen 2017; Lough/Tiessen/Lasker 2018). Thanks to 
this research, we now know much more about how diverse forms of international volunteering are associated with development outcomes (Lough/ Tiessen 2017; Lough/Tiessen/Lasker 2018; Tiessen/Grantham/Lough 2018; Tiessen/Lough 2018). On the other hand, only some of this research has incorporated the voice of community members and organizations that interact with volunteers. Previous research conducted by the special issue editors which was published in Voluntaris in 2018 resulted in improved understanding about how diverse forms of international volunteering are associated with capacity building and development outcomes from the perspective of partner organizations in the Global South (Lough/ Tiessen 2017; Lough et al. 2018; Tiessen/Grantham/Lough 2018; Tiessen/Lough 2018). However, the exploratory research also uncovered many additional gaps of express interest to volunteer-involving organizations. In particular, research from the perspective of partner organization staff about their experiences working with IDVs, including the relationship-building aspects of transnational interactions, as well as specific programmatic work carried out in collaboration between IDVs and partner organizations in support of GEWE remains a gap in scholarship.

\subsection{Incorporating Southern Voices in IDV Scholarship}

Building upon the success of the previous Voluntaris special issue, the goal of this collection is to further leverage the voices and the stories of Southern hosts to broaden this knowledge base. The research for this collection therefore adds to scholarship on IDVs, transnational actors, and international development; particularly the emphasis on agency of Southern partners and communities in development processes that affect their lives. Much of the theorizing on international volunteering has followed a critical theory approach (i.e., postcolonial and neoliberal critiques) that has originated from scholarship rooted in the Global North (Baillie Smith/ Laurie 2011; see Heron 2007; Georgeou/Engel 2011; Noxolo 2011; Perold et al. 2013; Tiessen/Kumar 2013). Building on existing scholarship on the human capabilities framework, our approach "underscores the potential for improved quality of life across the globe and allows for the consideration of other human capabilities and improvements stemming from good health or meaningful or loving relationships that have been linked to international volunteering" (Tiessen/ Lough/Cheung 2018:12).

Moving beyond the Northern-centric theoretical analysis of critical postcolonialism, this collection employs discursive normative theory (Nussbaum 2003; Kanbur/Shaffer 2007) and identity-based theories that highlight the importance of capacities and agency of traditionally conceived "recipients" of aid (see, in this collection, Shahadu Bitimsamli who considers masculinities; and Mpogazi and SaintDenis who draw on empowerment scholarship). These theoretical approaches are highly relevant to practice partners in the Global South that are firmly rooted 
in practice realities. However, they have received very little scholarly attention in studies of international volunteering (Tiessen/Lough/Cheung 2018). Greater attention to the agency, voice and social capital of those positioned in the Global South (see Loiseau et al. 2016; Perold et al. 2013; Tiessen 2018) informs both theoretical analysis and research methodologies that consider subaltern voices (Saffari 2016; Tiessen/Grantham/Lough 2018). In employing the theoretical and methodological lens of agency and human capability, we aim for a richer analysis of the perspectives and experiences of the Global South partners who work alongside IDVs on international development programming aiming to promote gender equality.

\subsection{International Volunteering as a Complementary Feminist Approach to Development Practice}

Compared to other aid approaches, some scholars have described volunteering as a particularly "feminist" approach that prioritizes human and relational strategies over heavy-handed technocratic development approaches (Devereux 2010; Tiessen/Grantham/Lough 2018). Operating within a relational approach to development, IDVs complement dominant technical and market-based approaches to international development, turning away from the strict association between development and economic growth to value the enhancement of human abilities and solutions (Devereux 2008; Lewis 2006). Consistent with this approach, we aim to investigate the degree to which international development volunteering programs operate within this feminist perspective, and how international development volunteering's relational approach may help to address SDG 5 targets focused on promoting gender equality and the empowerment of women and girls. As such, the focus on gender equality and women's empowerment (GEWE) is a central area of analysis across all papers. The papers in this collection focus on a range of themes specific to GEWE including equal rights, legal protections, political participation, economic empowerment, and gender relations.

The international voluntary sector, along with the volunteers that populate this sector, are important contributors to collaborative practice through knowledge sharing and the implementation of the SDGs. Unfortunately, lack of investment into research on volunteering in development has kept the contributions of this sector hidden, understudied and undervalued (Devereux/Guse 2012; Seelig/Lough 2015). To date, only a handful of qualitative studies have investigated the complementary contributions of international volunteering - pointing to qualities such as social capital, innovation, flexibility, challenging gender norms, improving human rights awareness, and building vertical "bridges" or relational networks with higher-level actors (Devereux 2010; Lough 2014; Burns et al. 2015; Lough 2015).

This collection helps to fill these gaps. As the papers in the issue illustrate, turning international targets and commitments to gender equality into practical action 
requires partnerships from diverse actors working across the local-international divide. Equipped with distinctive relational motivations and attributes, international volunteering is purportedly "well-placed to create pathways to economic empowerment of women and youth" (UNV 2017: 1). Despite the contributions referenced in global practice and policy documents, the evidence base to support claims of relational complementarity from international volunteering is still weakespecially in this field. To adequately capture the relational complementary contributions of VCP to gender equality, this collection illustrates diverse ways that volunteers engage in the processes and systems directed toward local change efforts.

Theoretically, relational outcomes such as inspiration, trust, networks, cross-cultural understanding, and interpersonal skills transfers are critical complements to technical development processes (Fukuda-Parr/Lopes/Malik 2002; Lough 2015). Pathways from international volunteer engagement to end-goals such as gender equality and other SDGs depend on achieving intermediary relational outcomes such as building mediating networks, altering gender norms through interpersonal engagement in open systems, and sharing skills through capacity-building strategies. Theories that measure relationship-based processes can capture this narrative by "linking the chain of causality within each step" from intermediary outcomes to distinctive contributions (Mattero/Campbell-Patton 2008: 43). By making these causal linkages, findings within these papers document how IDVs are instrumental to GEWE and related SDG outcomes.

Throughout this collection, the impact of IDVs in support of GEWE programming considers different approaches from Women in Development (WID) to Gender and Development (GAD). In brief, WID aims to increase women's access to resources and economic development, emphasizing inclusion, participation and the fulfillment of practical needs. GAD moves beyond the mere inclusion of women to consider the systemic reasons for exclusion and marginalization; the significance of addressing strategic gender interests; to show how gender relations are influenced by the gendered division of labour (Moser 1993); and to transform the structures of power to facilitate new opportunities for participation and empowerment (Parpart 2014). As a shorthand, WID and GAD enable theoretical analyses drawing on feminist scholarship to underscore the tensions and explanatory power of critical and postcolonial feminist theory and the contributions of feminist subaltern insights in relation to "othering" (Spivak 1999; Tiessen/Baranyi 2017), as universal aspects of women's experiences, instrumentalization of women for development outcomes (Tiessen 2015), and the prospects for feminist international relations (Tiessen/ Swan 2018).

These frameworks of analysis are important for making sense of the diverse approaches to GEWE programming and can be used to make sense of distinctive contributions of IDVs (skills and capacity building, relationship formation, etc.) 
and results (the changes that take place in gender equality measures through the synergies created through partner organization/IDV interactions). Taken together, these theoretical approaches provide new lenses to investigate and document whether the complementary contributions of international volunteerism truly support global partnership arrangements that can achieve end-goals of GEWE and related SDG outcomes (Schech et al. 2015). The eight thematic papers in this collection offer important insights into the processes and outcomes of interactions in transnational spaces focusing on themes of diverse experiences of empowerment; locally based interpretations and cultural adaptations of feminist principles and GEWE goals and priorities; and gender relations within partner organizations and between partner organizations, IDVs and community members.

\section{Methodology}

The methodology employed across all the papers in this collection reinforces the goals and objectives of this project by enhancing knowledge of collaborative, reciprocal, and solidarity-oriented practice through the inclusion of Global South perspectives in the design and implementation of research. The research methodology began by enhancing the capacity of emerging scholars (senior undergraduate and graduate students from Canada and graduate students or recent graduates from countries in the Global South) to design and carry out data collection, to transcribe, analyze and organize findings, and to write up thematic papers drawing on data across all country case studies. Where possible, locally-based researchers were hired to conduct the research. Three of the researchers engaged in data-collection in partner countries are locally based researchers (graduate students or recent graduates) and a fourth researcher is an international student studying in Canada who returned to his home country for data collection. The remaining five researchers were emerging scholars (senior undergraduate or graduate students) studying in Canada.

The research team worked closely with partner organization staff in ten countries in the research plan, helping with identification of interview participants, identifying communities to visit to learn about outcomes of development programming.

The research team took a "portfolio approach" to the study of international development volunteering. Consistent with the three sets of theoretical approaches underpinning this research project: (1) the normative co-generation of knowledge through shared responsibility between international researchers and local citizens in the Global South, (2) the relational complementarity of IDVs, and (3) the gendered analysis of outcomes advanced by IDVs. Working together, the research team developed research tools, contributed to the ethics application and were listed on the research project for the purpose of ethics clearance, and analyzed new and existing data through a gender lens. Partner organizations included in the study 
provided feedback on the research design and interview questions to ensure the cultural appropriateness of the study design and instruments used in this study.

Qualitative interviews and focus groups were carried out in a representative sample of ten countries in Africa, Asia and Latin America where Canada's VCP is actively engaged. ${ }^{1}$ The ten countries were selected as locations where VCAs have had longstanding commitments to sending IDVs.

Interviews were carried out with an average of two staff members per organization. One of the staff members held a senior position within the organization and the other interviewee was selected based on their experience working closely with IDVs. The interview participants included both men and women staff members. On average, 15 interviews were conducted in each of the ten countries with an equitable representation of men and women interviewees.

The interviews were open-ended and semi-structured with a common set of guiding questions used across all ten countries to ensure a level of consistency between interviews but also flexibility in responding, returning to questions, elaboration, story-telling, etc. With consent from the interviewees, the interviews were audio recorded. The majority of interviews were conducted in English but in some cases, interviews were conducted in French (in Senegal) and in Spanish (in Peru and Guatemala) or in Vietnamese (in Vietnam) and translated to English during the transcription stage.

Once all interviews were transcribed, the material was coded and analyzed, each researcher reviewed the full set of transcripts and coded the material to identify common themes throughout. Additional research assistants joined some of the original research team in the reviewing and coding of data, and these roles transformed into authorship of papers in this collection. Several themes emerged through the process of content analysis and those themes became the focus of this collection.

Document review of VCA reports and Government of Canada mid-term and endof-cycle reports (obtained through research placements in-country) was also conducted to provide additional context and insight. To conduct the document review, all authors were provided the country summary reports. Each author reviewed the summary reports in line with the themes specific to their papers to find key words, ideas, and themes that fit the general theme of their respective papers. Information was compiled into thematic-specific notes and trends were examined across subthemes. The authors then used specific quotes from those findings to provide rich examples and nuance to their papers.

Two in West Africa (Ghana and Senegal), four in East and South-East Africa (Uganda, Kenya, Tanzania and Malawi); two in Asia (Nepal and Vietnam) and two in Latin America (Peru and Guatemala). 
As this collection will illustrate, the data collected across the ten countries found that overall IDVs are important transnational actors working in partnership with Global South hosts to achieve common goals and priorities for gender equality and women's empowerment. The papers in this collection also provide important insights into common and shared goals of GEWE and some of the strategies and priorities needed to support improved GEWE programming in collaboration with partner organizations and local communities in partner organizations.

The findings from across the ten case studies provides valuable aggregate information to inform a deeper analysis of trends and impacts of gender equality programming outcomes resulting from interactions between IDVs and partner organization staff. Documentation of the role and impact of IDVs in the promotion of GEWE were catalogued in relation to the frames and approaches noted above and the tools to analyse the research findings were co-designed by the lead research team as well as and emerging scholars from Canada, the USA, and the Global South during the data analysis phase.

\section{Overview of Papers in the Collection ${ }^{2}$}

In the paper titled 'Capacity Building and Capability Development: Understanding the Relations of Power and Exchange Between International Development Volunteers and Partner Organizations and Communities', Sadat explores the collaborative process of capacity building and capabilities development among IDVs, partner organizations, and host communities in the Global South. Unique to her work is the focus on the power dynamics that characterize this transnational interaction between IDVs and partner organizations, and its influence on the quality of capacity building and capabilities development that takes place. Using the capabilities approach (Sen 1999; Nussbaum 2011) as a frame and drawing on data across all ten countries, she underscores the reciprocal and mutually beneficial nature of capacity building and capabilities development. The author shows that through their sustained interactions, IDVs built partner organizations' capacity through several measures like skills transfer, and technical and intercultural knowledge sharing while simultaneously gaining practical context-relevant knowledge and skills on GEWE from partner organizations.

Rouhani's paper, 'Creating cosmopolitan identities in transnational spaces to advance gender equality', highlights how IDVs' transnational relations with partner organizations in transnational spaces effects a shift in the latter's cosmopolitan and global citizenship perspectives as it relates to gender equality and empowerment. Evidence from the ten country case studies suggests that this cross-cultural

2 See information about the authors at the end of the special issue. 
interaction between IDVs and partner organizations (one based on reciprocity and mutual learning) was instrumental in introducing novel ideas that positively reshaped both parties' feminist values and perspectives, and consequently their cosmopolitan identities and global citizenship. Not only were partner organizations' capacities built through this interaction, but the process was also perceived to be an equal cosmopolitan exchange of values, norms, ideas and knowledge on gender equality and empowerment.

The third paper in this collection, 'Organizational Commitments to Gender Equality Programming: Resistance, Externalizing and Opportunities for Gender Mainstreaming', examines GEWE programming and IDV support for gender mainstreaming in development organizations. Lan Nguyen examines gender dynamics within development organizations as a factor for considering GEWE outcomes in beneficiary communities. The paper highlights the subordinate position of gender mainstreaming on partner organizations' agendas and their neglect of the intersectional and structural dimension of gender inequality. Nguyen's paper examines IDVs' contributions to - and the persistent challenges to - organizational change and gender mainstreaming faced by partner organizations.

In 'Strings Attached? How Global South partner organizations' perceptions of feminism shape their relationships with Feminist Foreign Policy Donors from the Global North', Laursen probes into partner organizations' perceptions of donor priorities and mandates, particularly Canada's Feminist International Assistance Policy. Using Coston's (1998) analytical framework, Laursen shows that partner organizations had varied levels of knowledge about the policies and varied capacities to benefit from the resources available through the policies. Her study also highlights that donor feminist priorities have also helped to amplify GEWE on the ground, but partner organizations have to negotiate the power differentials that characterize their relationship with donors. Specifically, she shows how partner organizations strategically exert their agency and autonomy when their feminist values were at odds with those espoused by Northern donors due to the latter's contextual disconnect.

'Social Innovation and Economic Empowerment as Opportunities for Gender Equality and Women's Empowerment in International Development Volunteering' by Tiessen, Laursen and Lough focuses on the contribution of IDVs to GEWE and social innovation programming in partner organizations and their host communities. The authors show that across the ten country case studies, IDVs initiated several innovative measures in the operations of partner organizations that positively impacted women's inclusion and participation in empowerment programs and the wider labour market. Such innovations, for example, targeted and alleviated structural barriers to women's participation such as their care work burden. In addition, partner organizations benefitted from IDVs' broad range of knowledge and skills 
to enhance the design and implementation of their GEWE policies and programs. The authors emphasize the need for local sensitivities and knowledge of cultures and communities to be effective, strategic, and impactful.

Using a transnational feminist lens, Shahadu Bitamsimli examines the experiences of partner organizations as they work with IDVs to deliver GEWE programs in the Global South. In Transnational Feminism as a Lens for Exploring Resistance, Cooperation and Collaboration with International Development Volunteers in Gender Equality and Women's Empowerment Programs, the author uncovers the harmonies and tensions inherent in partner organizations' relations with IDVs, and the range of strategies employed by partner organizations to navigate them. The exercise of agency echoes across Shadadu's account of partner organizations' strategies of resistance, cooperation, and collaboration across the country case studies. His paper centers on the important role that partner organizations and IDVs transnational engagement can play in tackling hostilities and resistance to the transformation of oppressive gender attitudes and institutions. It also notes that the realization of feminist goals is significantly tied to the recruitment of male allies to push the GEWE agenda. On this latter point, Shahadu Bitamsimli argues that male IDVs can exhibit alternative masculinities that transcend traditional gender roles which can then alter the patriarchal perspectives and attitudes of local communities in favour of GEWE.

In Women's Political Participation, Activism and Advocacy to Promote Gender Equality Facilitated by IDVs, Mpogazi is concerned with highlighting how IDVs support women's political participation as they mobilize in the grassroots to engage with both state and non-state political structures and networks. The author draws on data from across the country case studies to show how IDVs promoted women's political empowerment and leadership by providing mentorship and social support to women; providing technical assistance for gender advocacy; and equipping partner organizations with empirical evidence and skills to support their activism and advocacy on women's issues. The analysis also emphasizes the importance of informal grassroots organizing which is outside the formal political domain but equally necessary for realizing gender equality and empowerment. As well, the author calls for critical reflexivity on the part of IDVs for more effective and contextually relevant support to women's political participation and empowerment.

In International Volunteers as Empowerment Agents: Challenges and Opportunities of IDV Contributions to Women's Empowerment Programs in Partner Communities, Saint-Denis contends that the conceptualization of "empowerment" that IDVs promote in the Global South is limited and depoliticized by its neoliberal framing. She argues that empowerment has been reduced from a political concept to a buzzword concerned with economic liberalization of women through the transfer of skills and resources. Nonetheless, the author opines that IDVs can still contribute 
positively to empowerment by prompting transformation in local attitudes and perspectives on gender equality through the exchange of knowledge in formal and informal spaces. The author also acknowledges that IDVs helped to foster women's economic empowerment by combining strategies to promote critical analyses of structures of inequality that lead to economic inequality with relevant training and workshops to build their professional and entrepreneurial capacities. As challenges to IDVs' contribution to women's empowerment, Saint-Denis identifies cultural tensions which manifest when IDVs attempt to impose Western feminist ideals in the local context and when they dismiss local gender norms.

\section{Conclusion}

The collection concludes with a summary of the papers in the collection, recapping and synthesizing the key arguments presented by the authors in this special issue. Okoli situates the findings in the broader literature by discussing their implications for international development volunteering and GEWE programming. The author also recommends the prioritization of cultural orientation for IDVs before and during their placement; critical reflexivity in IDVs' interactions with locals; and IDVs increased engagement with local feminist scholarship and organizations in their attempts to promote GEWE programming. Okoli suggests that along with partner organizations' deliberate cultural orientation efforts, improved IDV preparation can facilitate cultural sensitivity and learning among IDVs and enhanced programmatic outcomes for partner organizations. This cultural learning can build on the mutual exchange of information and the generative nature of learning that transpires during collaborative and transnational work on GEWE, which can lead to the production and sharing of "transnational" knowledge.

Together, the papers in this collection provide an overview of the unique interactions and synergies created through the transnational relationships forged while IDVs collaborate with partner organizations in gender equality and women's empowerment programming. Across the ten countries in this study, important insights are gained about the nature of the distinctive contributions made by IDVs. Examples provided in the eight papers in this collection demonstrate the significance of the cultural contexts in which transnational actors operate and the specific strategies employed by partner organizations as they negotiate change in their collaborations with IDVs. The findings highlight valuable information about diverse contributions to empowerment (political, social, and economic) and deepen our understanding of gender relations to consider gender equality and empowerment in relation to structural realities and root causes of gender inequality.

The research also considers the value and impact of gender-focused social innovations, and the potential for transnational relations to enhance capacity building and global civic engagement specific to gender equality. 


\section{Acknowledgements}

Drs Tiessen and Lough wish to thank the Social Sciences and Humanities Research Council of Canada (SSHRC) for their generous support in funding that facilitated data collection in ten countries between 2018-2019, and for resources to support the open access of this publication. We also wish to thank the external reviewers for their helpful feedback on earlier drafts.

To conduct this research and to prepare these papers, we worked with a team of dedicated researchers from several countries. We are grateful to all members of the team who played important roles throughout the data collection, analysis and writing stages. In addition to the chapter authors, we also wish to thank the larger team who helped with the data collection and analysis for this collection. Many thanks to Ephron Gausi, a locally based researcher in Malawi who collected data and summarized findings; Liana Fraser, a Canadian-based graduate student who traveled to Uganda to carry out data collection and report writing in Uganda; and to Anne Shileche, a Kenyan Masters student studying in Canada who travelled to Kenya to complete data collection and report writing; Bryn Copp, an MA student in Canada who carried out data collection in Nepal; Adrienne Bolen, a Canadian student who travelled to Guatemala; Tabitha Mirza (co-author on a paper in this collection) who completed research in Tanzania; Somed Shahadu Bitamsimli, PhD student in Canada who carried out research in Ghana (and is author in this collection); Pascale Saint-Denis, an MA student who conducted research in Peru (and is an author in this collection); and Lan Nguyen, a PhD student who conducted research in Vietnam (and is an author in this collection) and Rika Mpogazi, a student in Canada who travelled to Senegal for data collection (and an author in this collection).

\section{Bibliography}

Baillie Smith, Matt; Nina, Laurie (2011): International Volunteering and Development: Global Citizenship and Neoliberal Professionalisation Today. In: Transactions of the Institute of British Geographers, vol. 36, no. 4, pp. 545-559.

Baillie Smith, Matt; Nina, Laurie; Griffiths, Mark (2018): South-South Volunteering and Development. In: The Geographical Journal, vol. 184, no. 2, pp. 158-168.

Burns, Danny; Picken, Alexandrea; Hacker, Elisabeth; Aked, Jody; Turner, Katie; Lewis, Simon; Lopez Franco, Erika (2015): The Role of Volunteering in Sustainable Development. https:// www.vsointernational.org/sites/default/files/the_role_of_volunteering_in_sustainable_ development_2015_vso_ids.pdf (6.8.2021)

Butcher, Jacqueline; Einolf, Christopher (2017): Perspectives on Volunteering: Voices from the South. Geneva.

Campbell Lehn, Carla (2015): Leading Big Volunteer Operations. In: Rosenthal, Robert J. (ed.): Volunteer Engagement 2.0: Ideas and Insights Changing the World. Hoboken, pp. 322-333. 
Chen, Li-Ju; Chen, Joseph S. (2011): The Motivations and Expectations of International Volunteer Tourist: A Case Study of "Chinese Village Traditions". In: Tourism Management, vol. 32, no. 2, pp. 435-442.

Clarke, John (2005): Welfare States as Nation States: Some Conceptual Reflections. In: Social Policy and Society, vol. 4, no. 4, pp. 407-415.

Della Porta, Donatella; Andretta, Massimiliano; Mosca, Lorenzo; Reiter, Herbert (2006): Globalization from Below: Transnational Activists and Protest Networks. Minneapolis/ London.

Devereux, Peter (2010): International Volunteers: Cheap Help or Transformational Solidarity Toward Sustainable Development, PhD thesis, Murdoch University. https://researchrepository.murdoch.edu.au/id/eprint/3551/ (6.8.2021).

Devereux, Peter (2008): International Volunteering for Development and Sustainability: Outdated Paternalism or a Radical Response to Globalisation? In: Development in Practice, vol. 18 , no. 3 , pp. $357-370$.

Devereux, Peter; Guse, Kornelia (2012): MDGs, Sustainable Development Goals and the Post 2015 Agenda: Opportunities for Consolidating the Recognition of Volunteerism, https:// forum-ids.org/wp-content/uploads/2012/08/2012-Discussion-Paper-Post-2015.pdf (6.8.2021).

Evans, Peter (1996): Introduction: Development Strategies Across the Public-Private Divide. In: World Development, vol. 24, no. 6, pp. 1033-1037.

Fukuda-Parr, Sakiko; Lopes, Carlos; Malik, Khaled (2002): Capacity for Development: New Solutions to Old Problems. London.

Georgeou, Nichole; Engel, Susan (2011): The Impact of Neoliberalism and New Managerialism on Development Volunteering: An Australian Case Study. In: Australian Journal of Political Science, vol. 46, no. 2, pp. 297-311.

GAC - Global Affairs Canada (2017): Canada's Feminist International Assistance Policy. https://www.international.gc.ca/world-monde/assets/pdfs/iap2-eng.pdf? ga $=2.222487771 .1927185083 .1622431587-1872577644.1613535683$ (6.8.2021).

Government of Canada (2020): Canada's Policy for Civil Society Partnerships for International Assistance - A Feminist Approach. https://www.international.gc.ca/world-monde/ issues_development-enjeux_developpement/priorities-priorites/civil_policy-politique _ civile.aspx?lang=eng (6.8.2021).

Hägel, Peter (2011): Transnational Actors. https://www.oxfordbibliographies.com/view/document/obo-9780199743292/obo-9780199743292-0016.xml (6.8.2021).

Haas, Benjamin; Repenning, Alexander (2018): Transnational knowledge in volunteering for development - A postcolonial approach to weltwärts. In: Transnational Social Review, vol. 8 , no. 1 , pp. 34-49.

Helms, Sara; McKenzie, Tom (2014): Gender Differences in Formal and Informal Volunteering in Germany. In: Voluntas, vol. 25, no. 4, pp. 887-904.

Heron, Barbara (2007): Desire for Development: Whiteness, Gender, and the Helping Imperative. Waterloo.

Johnson, Tobi (2015): Big Shifts That Will Change Volunteerism for the Better. In: Rosenthal, Robert J. (ed.): Volunteer Engagement 2.0: Ideas and Insights Changing the World. Hoboken, pp. 3-19.

Kanbur, Ravi; Shaffer, Paul (2007): Epistemology, Normative Theory and Poverty Analysis: Implications for Q-Squared in Practice. In: World Development, vol. 35, no. 2, pp. 183-196. 
Larsen, Marianne A. (2016): International Service Learning: Engaging Host Communities. New York.

Lee, Young-Joo; Doyeon, Won (2018): Understanding International Volunteering: Who is Most Likely to Participate? In: Journal of Nonprofit and Public Sector Marketing, vol. 30, no. 1, pp. 95-110.

Lewis, David (2006): Globalization and International Service: A Development Perspective. In: Voluntary Action, vol. 7, no. 2, pp. 13-26.

Lindsey, Rose; Mohan, John; Bulloch, Sarah; Metcalfe, Elizabeth (2018): Why People Volunteer: Contextualising Motivation. In: Lindsey, Rose; Mohan, John; Bulloch, Sarah; Metcalfe, Elizabeth (ed.): Continuity and Change in Voluntary Action: Patterns, Trends and Understandings. Bristol/Chicago, pp. 113-152.

Loiseau, Bethina; Sibbald, Rebekah; Raman, Salem A.; Darren, Benedict; Loh, Lawrence C.; Dimaras, Helen (2016): Perceptions of the Role of Short-Term Volunteerism in International Development: Views from Volunteers, Local Hosts, and Community Members. In: Journal of Tropical Medicine, pp. 1-12.

Landolt, Laura K. (2004): (Mis)constructing the Third World? Constructivist analysis of norm diffusion. In: Third World Quarterly, vol. 25, no. 3, pp. 579-591.

Lough, Benjamin J. (2015): The Evolution of International Volunteering. https://www. researchgate.net/publication/282567051_The_Evolution_of_International_Volunteering (6.8.2021).

Lough, Benjamin J. (2014): Social Work Perspectives on International Volunteer Service. In: The British Journal of Social Work, vol. 44, no. 5, pp. 1340-1355.

Lough, Benjamin J.; Tiessen, Rebecca (2018): How do International Volunteering Characteristics Influence Outcomes? Perspectives from Partner Organizations. In: Voluntas, vol. 29, no. 1 , pp. 104-118.

Lough, Benjamin J.; Tiessen, Rebecca; Lasker, Judith N. (2018): Effective Practices of International Volunteering for Health: Perspectives from Partner Organizations. In: Globalization and Health, vol. 14, no. 11, pp. 1-11.

Lough, Benjamin J.; Xiang, Xiaoling (2016): Skills-Based International Volunteering Among Older Adults from the United States. In: Administration \& Society, vol. 48, no. 9, pp. 10851100.

Macdonald, Laura (2018): Canada Goes Global: Building Transnational Relations between Canada and the World, 1968-2017. In: Canadian Foreign Policy Journal, vol. 24, no. 3, pp. 358-371.

Mati, Jacob Mwathi (2017): Models, Developments, and Effects of Transborder Youth Volunteer Exchange Programs in Eastern and Southern Africa. In: Butcher, Jacqueline; Einolf, Christopher (ed.): Perspectives on Volunteering: Voices from the South. Geneva, pp. 129-148.

Mattero, Minna; Campbell-Patton, Charmagne (2008): Measuring the Impact of Youth Voluntary Service Programs: Summary and Conclusions of the International Experts' Meeting. https://www.issuelab.org/resources/3079/3079.pdf (6.8.2021).

Moore McBride, Amanda; Lough, Benjamin J. (2010): Access to International Volunteering. In: Nonprofit Management \& Leadership, vol. 21, no. 2, pp. 195-208.

Moser, Caroline (1993): Gender Planning and Development: Theory, Practice and Training. London. 
Noxolo, Patricia (2011): Postcolonial Economies of Development Volunteering. In: Pollard, Jane Shelley; McEwan, Cheryl; Hughes, Alex (ed.): Postcolonial Economies. London/New York, pp. 205-228.

Nussbaum, Martha (2003): Capabilities as Fundamental Entitlements: Sen and Social Justice. In: Feminist Economics, vol. 9, no. 2-3, pp. 33-59.

Nye, Joseph; Keohane, Robert O. (1971): Transnational Relations and World Politics: An Introduction. In: International Organization, vol. 25, no. 3, pp. 329-349.

Omoto, Allen; Malsch, Anna; Barraza, Jorge (2009): Compassionate Acts: Motivations for and Correlates of Volunteerism among Older Adults. In: Fehr, Beverley; Sprecher, Susan; Underwood, Lynn (ed.): The Science of Compassionate Love Theory, Research, and Applications. Malden/Oxford, pp. 257-282.

Ostrom, Elinor (1996): Crossing the Great Divide: Coproduction, Synergy, and Development. In: World Development, vol. 24, no. 6, pp. 1073-1087.

Palacios, Carlos M. (2010): Volunteer Tourism, Development and Education in a Postcolonial World: Conceiving Global Connections Beyond Aid. In: Journal of Sustainable Tourism, vol. 18 , no. 7 , pp. 861-878.

Parpart, Jane L. (2014): Exploring the Transformative Potential of Gender Mainstreaming in International Development Institutions. In: Journal of International Development, vol. 26, no. 3, pp. 382-395.

Perold, Helene; Graham, Lauren A.; Mazembo Mavungu, Eddy; Cronin, Karena; Muchemwa, Learnmore; Lough, Benjamin J. (2013): The Colonial Legacy of International Voluntary Service. In: Community Development Journal, vol. 48, no. 2, pp. 179-196.

Risse, Thomas (2013): Transnational Actors and World Politics. In: Carlsnaes, Walter; Risse, Thomas; Simmons, Beth A. (ed.): Handbook of International Relations. London, pp. 426-451.

Roman, Monica; Muresan, Laura-Mihaela; Manafi, Ioana; Marinescu, Daniela (2018): Volunteering as International Mobility: Recent Evidence from a Post-Socialist Country. In: Transnational Social Review, vol. 8, no. 3, pp. 258-272.

Saffari, Siavash (2016): Can the Subaltern be Heard?: Knowledge Production, Representation, and Responsibility in International Development. In: Transcience Journal, vol. 7, no. 1, pp. 36-46.

Schech, Susanne; Mundkur, Anuradha; Skelton, Tracey; Kothari, Uma (2015): New Spaces of Development Partnership: Rethinking International Volunteering. In: Progress in Development Studies, vol. 15, no. 4, pp. 358-370.

Shriwise, Amanda (2020): Advancing Transnational Approaches to Social Protection in the Global South. In: Schmitt, Carina (ed.): From Colonialism to International Aid: External Actors and Social Protection in the Global South. Switzerland, pp. 19-42.

Smith, Peter (2014): International Volunteer Tourism as (De)commodified Moral Consumption. In: Mostafanezhad, Mary; Hannam, Kevin (ed.): Moral Encounters in Tourism. London, pp. 31-45.

Spivak, Gayatri Chakravorty (1999): A Critique of Postcolonial Reason: Toward a History of the Vanishing Present. Cambridge/London.

Tiessen, Rebecca (2018): Learning and Volunteering Abroad for Development: Unpacking Host Organisation and Volunteer Rationales. Abingdon/New York.

Tiessen, Rebecca (2015): Gender Essentialism in Canadian Foreign Aid Commitments to Women, Peace, and Security. In: International Journal, vol. 70, no. 1, pp. 84-100. 
Tiessen, Rebecca; Baranyi, Stephen (2017): Obligations and Omissions: Canada's Ambiguous Actions on Gender Equality. Montreal.

Tiessen, Rebecca; Lough, Benjamin J.; Cheung, Samuel (2018): Introduction: A Theoretical and Methodological Case for Examining Agency and Power Relations North-South Volunteering Research Collaborations. In: Tiessen, Rebecca; Lough, Benjamin J.; Grantham, Kate (ed.): Insights on International Volunteering. Perspectives From the Global South. Germany, pp. 7-20.

Tiessen, Rebecca; Paritosh, Kumar (2013): Ethical Challenges Encountered on Learning/Volunteer Abroad Programmes for Students in International Development Studies in Canada: Youth Perspectives and Educator Insights. In: Canadian Journal of Development Studies / Revue canadienne d'études du développement, vol. 34, no. 3, pp. 416-430.

Tiessen, Rebecca; Rao, Sheila; Lough, Benjamin J. (2021): International Volunteering as Transformational Feminist Practice for Gender Equality. In: Journal of Developing Societies, vol. 37, no. 1, pp. 30-56.

Tiessen, Rebecca; Swan, Emma (2018): Canada's Feminist Foreign Policy Promises: An Ambitious Agenda for Gender Equality, Human Rights, Peace, and Security. in: Hill, Norman; Lagassé, Philippe (ed.): Justin Trudeau and Canadian Foreign Policy. New York, pp. 187-205.

Trau, Adam M. (2015): Challenges and Dilemmas of International Development Volunteering: A Case Study from Vanuatu. In: Development in Practice, vol. 25, no. 1, pp. 29-41.

United Nations (2016): Gender Equality 'Greatest Human Rights Challenge of Our Time', Secretary-General Tells High-Level Panel on Women's Economic Empowerment. https:// www.un.org/press/en/2016/sgsm18122.doc.htm (6.8.2021).

United Nations Volunteers (2017): Volunteer Solutions for Poverty Reduction and Economic Empowerment of Women and Youth. https://www.unv.org/Success-stories/Volunteer-solutions-poverty-reduction-and-economic-empowerment-women-and-youth (6.8.2021).

Zwingel, Susanne (2012): How Do Norms Travel? Theorizing International Women's Rights in Transnational Perspective. In: International Studies Quarterly, vol. 56, no. 1, pp. 115-129. 